\title{
Grandparents Affected by Parental Divorce: A Population at Risk?
}

\author{
Jane E. Myers and Novella Perrin
}

\begin{abstract}
When parents divorce, grandparents who have bonded with grandchildren may be affected, particularly when denied visitation. In this article the author reviews normative aspects of grandparenthood and how grandparents are affected by parental divorce. Legal and ethical issues and counseling interventions are discussed.
\end{abstract}

$\mathrm{T}$ he United States currently has the highest divorce rate in the world (Macionis, 1987), with more than one in every two first marriages ending in divorce. More than $60 \%$ of divorces occur in families with at least one minor child (Spanier \& Glick, 1981). Because of increased life expectancies in this century, most of these children will have living grandparents. One common concomitant of divorce is a disruption or severance of certain family relationships, such as the relationship between grandparents and grandchildren.

Although the age at which one first becomes a grandparent ranges from 18 years to older than 100 years, the focus of the current discussion will be on those grandparents in middle age ( 40 to 65 years of age) and particularly those in later life (over age 65). More than $75 \%$ of older persons are grandparents (Troll, 1980), and more than $40 \%$ are also great-grandparents (Troll, Miller, \& Atchley, 1979).

When the statistics on divorce are combined with the numbers of older persons who are grandparents, a possible conclusion is that potentially large numbers of older persons may be at risk of disrupted or severed relationships with grandchildren as a result of parental divorce. There is little available literature to assist counselors and human development professionals in determining which grandparents may be most likely to exhibit emotional distress and what types of helping interventions may be most useful to them. This article is an attempt to provide needed information to assist in the identification of at-risk clients and of effective helping interventions to address their concerns.

The first section provides an overview of grandparenthood as a normative transition with an enormous diversity of individual response. Ways in which grandparents are affected by parental divorce are discussed in the next section, followed by a review of ethical and legal issues that may arise in counseling grandparents when parents divorce. The question of whose rights are most important-those of the grandparent or the grandchild-is central to this discussion. Implications for counselors and human development professionals are provided, as well as suggestions for needed research. Resources are given for additional information to assist grandparents who are or may become in need of assistance in coping with the effects of parental divorce on relationships with their grandchildren.

\section{GRANDPARENTHOOD: A NORMATIVE TRANSITION}

\section{Timing and Development}

Grandparents have little, if any, control over the timing of becoming a grandparent. They may have extensive control, however, over their own emotional investment in being a grandparent. The diversity in age, life stage, and life circumstances affect the development of grandparenting roles. For example, persons who become grandparents in mid-life tend to be more active in careers and parenting than are older persons, and have less time to devote to grandparenting (Johnson, 1985).

Erikson (1963) defined the central psychosocial crisis of mid-life as one of generativity. Mid-life adults are most concerned with leaving something of value to the next generation, or with helping their teenage children to become responsible and happy adults (Havighurst, 1972). As teenage children reach maturity, parents enjoy newfound freedom from child-rearing responsibilities. Many mid-life adults are often not ready to take an active role in grandparenting.

Older persons, particularly those in retirement, may have more discretionary time to devote to grandparenting. Older adults face the central psychosocial task of achieving ego integrity (Erikson, 1963); they are concerned with whether or not their lives have been lived in a satisfying manner. Relationships and choices may become increasingly important, with family relationships often becoming a central focus. Generativity issues may also resurface, leading to greater desire for relationships with grandchildren. During retirement, older persons commonly experience both a greater amount of free time and a reduction in available social roles (e.g., worker, perhaps spouse). Hence, older persons may have both the time and inclination to establish strong relationships with their grandchildren. Thus, it is impossible to understand an individual grandparent's reactions to grandparenting in the absence of knowing his or her age, life roles and circumstances, and current developmental challenges, as well as considering the continual transformation of relationships during the maturation of grandchildren.

\section{Grandparenting Roles and Styles}

Grandparenting roles are highly variable, because they are based on individual choice and many other factors. Furthermore, these roles will change over time as a particular grandchild ages and his or her life circumstances change. Defining grandparenting roles and styles is made even more difficult when considering the possibility (and probability) of having simultaneous yet different relationships among grandchildren and grandparents of different ages.

Grandparent roles are multidimensional in nature and have no clearly identified normative expectations (Troll, 1980). Numerous researchers have attempted to categorize grandparenting roles (Kornhaber \& Woodward, 1981; Nahemow, 1985; Neugarten \& Weinstein, 1964; Robertson, 1977). What most typologies share is a recognition that grandparent roles are changing as persons become grandparents earlier in life. In the past, grandparents were seen as family historians, mentors, and often storytellers. They were distant role models of moral development who perceived indulgence as a right of grandparenthood. New roles for grandparents are increasingly less formal and based more on intermittent contact and playfulness. 
In general, grandparents seem to create their own roles, based on their needs, the needs of their grandchildren, the expectations of their adult children, and external (e.g., geographic) factors. There is some evidence that persons are more accepting of the grandparenting role when it occurs "on time" for them (Bengtson, 1985). For example, parents of teenage mothers may feel they are forced into the role of an older person while still young. Similarly, persons in mid-life may associate grandparenting with aging, thus rejecting an active role with grandchildren.

\section{Family Dynamics Affecting Grandparenthood}

The relationship between grandparents and their grandchildren is not a direct generational tie, as is true with the relationship between parents and children, but rather is intergenerational (i.e., skips one or more generations) and is mediated through the children's parents (Robertson, 1977). Thus, the nature and quality of the relationship between grandparents and their adult children is a primary factor affecting grandparent-grandchild bonding. Adult children are empowered relative to both their children and parents (Matthews \& Sprey, 1984), and thus to a large extent can control relationships with each generation as well as between the generations. Grandparents who have good relationships with their adult children are much more likely to have access to their grandchildren and stronger ties may develop (Nahemow, 1985).

Grandparents can influence parent-child and other family relationships for better or worse. In many families, grandparents provide financial support, which significantly affects the quality of life for grandchildren (Tinsley \& Parke, 1984). Grandparents have been shown to act as a "stress buffer," arbiter of family disputes (Bengston, 1985), and a source of "roots" or sense of family ancestry (Hagestad, 1985). The role of grandparent as family historian can have a positive influence on parent-child relationships by telling about what the parents were like when they were young (Barinowski, 1982). Grandparents may provide significant emotional support for grandchildren during marital and family conflicts (Denham \& Smith, 1989).

Alternately, grandparents can have an adverse effect on grandchildren through their influence on parents as individuals and their impact on the marital adjustment of parents. For example, Denham and Smith (1989) discussed the tension that may be created in families when mothers-in-law interfere with or express opposition to parental choices relative to homemaking and child rearing. Grandparents who interfere with parental discipline, siding with either parent or child, can create or exacerbate disharmony in a family unit. Family conflict is increased when parents divorce and grandparent visitation becomes a contested issue (Derdeyn, 1985).

A further source of tension may be conflicts of interest between the generations (Orr \& Van Zandt, 1987). Children may feel cheated when family resources must be used to assist an aging parent. On the other hand, grandparents may feel burdened when asked to provide child care, which limits their freedom to choose other activities (Cherlin \& Furstenberg, 1986).

Although we were unable to find any research dealing specifically with intergenerational abuse, we conjecture that grandparents themselves are not universally caring persons. Grandparents who are abusive-physically, sexually, or emotionally-can have a devastating effect on the lives of their grandchildren.

\section{Additional Factors Affecting the Grandparent-Grandchild Bond}

In addition to the variables discussed earlier, factors that may affect the bonding between grandparents and grandchildren include the age of the grandchild, geographic proximity and frequency of contact, sex, and culture. Sprey and Matthews (1982) studied the dynamics of grandparenting and concluded that relationships differ between grandparents and grandchildren of different ages. Closer bonds develop between grandparents and very young children than between grandparents and older children and adolescents. Younger children may have fewer competing demands to affect time spent with grandparents. On the other hand, when parents postpone the birth of children until they themselves are older, and thus more independent from their own parents, the result is to limit grandparent involvement with grandchildren, partly through a greater age differential created between the oldest and youngest generations (George, 1980).

Geographic proximity sets realistic limitations on the amount of contact grandparents can have with their grandchildren. Cherlin and Furstenberg (1986) found that living in close geographic proximity accounted for $62 \%$ of the variance and was the single most important factor affecting grandparent-grandchild visits. There is some evidence that the closeness of the bond that develops is affected even more by frequency of contact than by geographic distance (Orr \& Van Zandt, 1987). Harris and associates (1975) reported data from a national study, which indicated that $75 \%$ of all grandparents had seen at least one grandchild in the past week and $50 \%$ had seen one in the last day or two. Of course, the quality of the contacts is not reflected in these data. Grandparents act as societal agents and role models for sex role socialization of grandchildren (Thomas \& Datan, 1985). In addition, they teach grandchildren skills, hobbies, and sports. It seems that grandmothers have a much greater impact on grandchildren as a result of greater contact. Grandfathers, in contrast, have low levels of interaction with grandchildren and give lower priority to the grandparent role (Kivett, 1985).

Sprey and Matthews (1982) reported that the economic as well as emotional dependence of parents on their parents decreases with age and varies by sex, educational status, and socioeconomic status. There also seem to be cultural differences in the grandparent role, with Black families in particular demonstrating greater involvement between grandchildren and grandparents (Cherlin \& Furstenberg, 1986). Black grandmothers frequently are involved as care givers or surrogate mothers to grandchildren.

\section{THE EFFECTS OF DIVORCE ON GRANDPARENTS}

Even adult children who are emotionally close to their parents frequently fail to talk about their marital problems with them. Consequently, fewer than half of all grandparents report being aware of an impending separation before it occurs (Cherlin \& Furstenberg, 1986). Grandparents must adjust to their children's marital breakup (which often occurs in contradiction to family values held dearly by the older generation), as well as the impact on their relationships with grandchildren. Many of the effects of divorce on grandparents can be predicted based on the preceding discussion of normative aspects of grandparent roles. Any deviation from "normal" can be painful. The effects of parental divorce are discussed in this section in relation to grandparent roles, custody, family patterns and responses, and emotional reactions.

\section{Grandparent Roles}

Divorce creates opportunities as well as problems for grandparents (Cherlin \& Furstenberg, 1980). On the one hand, there are opportunities to provide material assistance, child care, advice, and support. On the other hand, relationships may be restricted in new ways as a result of custody awards. A great deal of ambiguity ma $j$ exist, leaving grandpar- 
ents to struggle to find a balance between doing too much and doing too little.

According to Kivnick (1981), "Grandparenthood can facilitate an individual's development as he or she moves through the roles of child, parent, and grandparent" (p. 62). To the extent that grandparents are denied access to grandchildren as a result of divorce, they may experience difficulty in resolving their own developmental issues, feel a sense of dissatisfaction with their lives, or feel that some part of themselves is missing or incomplete. A variety of possible roles for grandparents in interacting with grandchildren was mentioned earlier. Divorce may result in fewer opportunities to engage in any of these roles, leaving a void in the life of the grandparent.

The possibility of divorce leads some grandparents to remain emotionally uninvolved in their children's family life (Matthews \& Sprey, 1984). It seems that the greater the personal investment in the grandparent role and the greater the pre-divorce frequency of contact, the more distress will be felt when grandparents are denied access to grandchildren following a divorce.

\section{Custody}

Because parents control the access of grandparents to their grandchildren, divorce clearly creates challenges to the maintenance of family ties. Unfortunately, custody awards often lead to a severance of grandparent-grandchild contact and bonds. Because custody is most frequently awarded to mothers, maternal grandparents are more likely to be able to maintain contact with grandchildren than are paternal grandparents. They are also much more likely to be called upon for emotional and financial support (Matthews \& Sprey, 1984).

Within a few years after divorce, on the average, noncustodial grandparents (i.e., parents of the noncustodial parent) live further away from their grandchildren, provide less financial support, and see them less often than do parents of the custodial parent (Cherlin \& Furstenberg, 1986). Parents may act punitively toward grandparents, purposely denying access to grandchildren to sever family ties (Wilson \& DeShane, 1982). Clearly, in-law grandparents are most likely to suffer the loss of grandchild contact following parental divorce.

\section{Family Patterns and Responses}

Custodial grandparents also may experience a major shift in roles, but in an opposite direction from noncustodial grandparents. Parents of custodial parents, most often single mothers, are called upon for increased emotional support, financial assistance, help with child care, and so forth. Grandparents with the resources to do so may find themselves providing large amounts of both material and emotional support, sometimes to the point that they find themselves living in three-generational homes as companion and friend to their daughter and surrogate parent to their grandchildren. The fusing of two adult households is not always a smooth process. Preexisting, unresolved, and unsatisfying family relationships may surface at some point to disturb the already shaky family equilibrium.

Grandparents must make choices when their children divorce (Johnson, 1985). They can remain aloof or become involved. Often, involvement leads to overinvolvement, financial strain, and role strain as they find themselves providing more family care and having less time and energy to invest in other roles. In regard to values, they must decide how to react to the more permissive life-styles of their children.

Should the custodial parent remarry, another renegotiation of roles will be required. Grandparents living with their adult children and grandchildren may expect once again to set up a separate household.
This can be a lonely transition, especially for older widowed persons. At this time, new sets of grandparents are acquired. The divorce and remarriage of grandparents themselves may add to the number of possible kinship ties. Parents may find it necessary to limit the range of grandparent choices for practical as well as emotional reasons, while grandparents may seek means to continue their relationships with their grandchildren (Sprey \& Matthews, 1982).

When parents remarry, new step-grandparents are placed in an awkward position. They are often not well integrated into the remarriage family life (Cherlin \& Furstenberg, 1986). There is some evidence that step-kin relationships are influenced by the age of the child. Younger step-grandchildren will bond more readily with step-grandparents, while older step-grandchildren may fail completely to develop an attachment with new step-grandparents. Thus, grandparents may be denied access to their own grandchildren as a result of divorce, while being denied emotional access to possible new sets of grandchildren who happen to be older when new families are formed through remarriages of adult children.

\section{Emotional Reactions}

Kivnick (1981) studied the relationship between grandparenthood and mental health. She noted a surprising tolerance for disappointment and helplessness in grandparenthood and suggested several possible explanations. It could be that older persons passively tolerate disappointments based on their perceptions of societal expectations. Or, it could be that the " peripheral status to which many people relegate grandparenthood somehow suggests that related disappointments are of little consequence and must therefore be endured" (p. 156). Or, perhaps grandparents simply do not recognize disappointments in grandparenthood, because it is has not been widely recognized as a subject for emotional response.

The loss of the grandparent-grandchild bond is accompanied by grief and often anger. When the parent is an only child, severance of the grandparent-grandchild relationship can eliminate an older person's sense of biological renewal and ties with future generations. Unmet, disappointed grandparent expectations can be a very real source of distress, pain, and depression. These feelings may be heightened and further complicated by the legal and ethical aspects of grandparents' rights, discussed in the following section.

\section{LEGAL AND ETHICAL ISSUES}

In cases of parental divorce, grandparent visitation can and increasingly does become a legal issue. The question of rights is central to legal discussions but is complicated by a consideration of whose rights are most important-those of grandparents or grandchildren? Should legislation focus on the best interest of the child or the needs of the grandparents? Baum (1984) reviewed current and past laws concerning parental rights and concluded that grandparents' rights to visitation or custody depend on the rights and best interests of grandchildren.

Derdeyn (1985) reviewed issues in grandparent visitation legislation and concluded that major considerations are animosity between parents and grandparents, psychological parenthood, conflicts of loyalty, and child development. Grandparent visitation has the potential to create increased tension and conflict in divorced families when animosity exists between parents and grandparents, both of whom may displace their disappointment, frustration, and anger onto grandchildren. Grandparents who participated in rearing their grandchildren either before or after a divorce (i.e., psychologically functioned as parents or surrogate parents), and who are later denied visitation, may experience a keen sense of loss. Furthermore, children in such circumstances who were 
parented by both parents and grandparents may experience conflicts of loyalty when visitation becomes an issue. The developmental stage of the child can affect visitation decisions, because, as noted earlier, grandparent-grandchild bonding is less likely to occur in blended families when children are older.

Adoption further complicates the issue. Courts have ruled that grandparents' rights are "derivative of the rights of biological parents, so when an adoption decree terminates parental rights, the rights of grandparents also are terminated' '(Derdeyn, 1985, p. 279). Thus, access to grandchildren may be legally denied.

All states now have grandparent visitation legislation, though the provisions are not uniform across states (House Committee on Education and Labor, 1985). Barineau (1984) reviewed existing legislation and court cases concerning grandparent rights. In all cases, when grandparents must seek legal means of gaining access to their grandchildren, conflict with parents is inevitable. The courts are left to determine the impact of this conflict as a disruptive force in the child's development. Furthermore, the preference of the child must be considered, leading to emotionally volatile and confusing courtroom appearances for children. The aftermath is painful for all concerned. Yet, Barineau concluded that grandparent rights should be upheld, because "grandparents can provide the grandchild with a stable relationship and unconditional love when his [or her] world is turned topsy-turvy due to the dissolution of his [or her] parents' marriage" (p. 178).

Both grandparents and grandchildren may be casualties of parental divorce, with no institutionalized guidelines for postdivorce relationships. Even the chance to say goodbye may be difficult or impossible in the case of angry parents. When all contact with the noncustodial side of the family is denied or restricted, grandparents do not have the authority to by-pass the custodial parent and talk directly with their grandchildren about their feelings (Cherlin \& Furstenberg, 1986). Grandparents may be left with significant unfinished business with their grandchildren, experiencing a loss that they must grieve and somehow resolve.

\section{IMPLICATIONS FOR COUNSELORS AND HUMAN DEVELOPMENT PROFESSIONALS}

Grandparents most at risk of experiencing a significant sense of loss when parents divorce can be identified based on several factors. These include the closeness of the prior relationship with grandchildren, investment in the grandparent role, the nature of relationships with adult children, the outcome of custody decisions, the nature of the relationship with the custodial parent, and whether adoption is involved or not. Grandparents who were close to grandchildren prior to divorce and who are denied access to them after divorce are obviously most at risk. Usually these will be the noncustodial grandparents, and most often the paternal grandparents.

When grandparents are called on to provide financial, material, and emotional support, the potential for burden and stress results. Grandparents may need help in setting limitations for family involvement to prevent an overload situation. When grandparents and their adult children begin to share a household after divorce, family counseling can be useful to help all family members articulate their expectations and concerns. Daily living rules as well as emotional interactions may need to be negotiated in multigenerational households.

Helping professionals should be aware of both legal and ethical issues that may arise when working with grandparents after parental divorce. It is desirable but not always possible to have all affected family members participate in counseling. The fundamental rights of children as well as grandparents need to be considered and openly discussed, particularly when they are in conflict. Certainly, the need to clarify who is the client will be a continuing concern throughout any intervention process, as the answer to the question is not always readily apparent.

When grandparents are permanently denied access to their grandchildren, they may need assistance in expressing their grief and coping with feelings of depression, disappointment, loss, and unfinished business. The inability to feel a sense of biological renewal when facing the end of one's life can be particularly painful for some grandparents. One option is for older persons to fill the role of adopted grandparent, when such roles are available.

Not all affected grandparents might choose to adopt grandchildren. Family relationships and love relationships cannot so easily be mandated or developed. It will be necessary to educate potential grandparents about the need and possible benefits of involvement with foster grandchildren. Furthermore, having once been denied access to their own grandchildren, grandparents may protect themselves from future disappointments by choosing not to interact with children at all. Education of parents, children, and older persons may be required before such initiatives can be successful.

Counselors can take both reactive and proactive stances in working with grandparents affected by divorce. In a reactive manner, they can provide a listening ear, empathy, and encouragement to children and grandparents who are enduring the emotional consequences of separation. In so doing, it will be important to explore with the grandparents the salience of the grandparent role and the importance of grandchildren in their lives. The frequency of contact, both pre- and postdivorce, should be assessed. Taking the time to explore the functions grandparenting served can be helpful in determining ways to fill the void left when grandparenting roles are curtailed or eliminated.

It is important to determine the nature of relationships with the custodial and noncustodial parent, as well as the grandparent's personal reactions to the divorce. Helping the grandparents cope with separation and loss of relationships with adult children and in-laws, as well as grandchildren, may be necessary. In some instances, surrogate or substitute relationships may be helpful and should be encouraged. It is important for counselors to assess the potential for effectiveness of such relationships before suggesting them to individual older persons.

Because grandparenthood is not a central issue in many families, however, this reactive stance will "miss" many of the persons who most need our help. It is commonly known that older persons are reluctant to seek counseling, even when it is readily available. Clearly, a proactive role for counselors is needed. In the broadest sense, this role requires counselors to be advocates for the needs of grandparents and grandchildren. Support of grandparents' rights legislation in each of the states is important, as well as support of such programs as "adopt-a-grandparent." Advocacy to protect the needs and rights of all family members requires counselors to consider the emotional consequences of separation for extended kin. Education of family members for roles they will experience across the life span is becoming an increasingly important concern. Preventive efforts require an understanding of the needs of individuals across the life span and how these needs are affected by multigenerational interaction. Research is lacking in this regard.

Research is also needed to guide helping interventions in the area of grandparent-grandchild relationships. We could find no studies that address either individual or group counseling strategies to assist older persons in dealing with the aftermath of parental divorce. Only one study of the value of adopted grandparents was found (Whitley \& Others, 1976). Although positive benefits of the adopted relationship were found, the study included only nursing home residents and a class of elementary school students. More than $95 \%$ of older persons do not 
reside in nursing homes; thus, the extent to which the results of this one study can be generalized is limited.

Where family separation occurs and legal help is needed, counselors must be prepared to provide referral and follow-up services. Counselors should be aware of available resources to help parents, grandparents, and grandchildren, depending on the needs of the persons involved. Perhaps the greatest barrier to be overcome in helping grandparents and grandchildren lies in the awareness of counselors that the relationship between these persons is important and even necessary for growth, development, and life satisfaction of those involved.

\section{REFERENCES}

Barineau, S. L. R. (1984). Grandparental rights to visitation and custody: A trend in the right direction. Cumberland Law Review, 15-16, 162-178.

Barinowski, M.D. (1982, November). Sex differences in adolescents' relations with grandparents. Paper presented at the annual scientific meeting of the Gerontological Society of America, San Antonio, TX.

Baum, F. E. (1984). Social change and family policies. Free papers, part 4 Papers presented at the International Committee on Family Research Seminar, Melbourne, Australia.

Bengtson, V. L. (1985). Diversity and symbolism in grandparental roles. In V. L. Bengtson \& J. F. Robertson (Eds.) Grandparenthood (pp. 11-25). Beverly Hills: Sage.

Cherlin, A. F., \& Furstenberg, F. F. (1986). The new American grandparent: A place in the family, a life apart. New York, NY: Basic Books.

Denham, T. E., \& Smith, C. W. (1989). The influence of grandparents on grandchildren: A review of the literature and resources. Family Relations, 38, 345-350.

Derdeyn, A. P. (1985). Grandparent visitation rights: Rendering family dissention more pronounced? American Journal of Orthopsychiatry, 55(2), 277-287.

Erikson, E. (1963). Childhood and society. New York: Norton.

George, L. K. (1980). Role transitions in later life. Monterey, CA: Brooks/Cole. Hagestad, G. O. (1985). Continuity and connectedness. In V. L. Bengtson \& J. F. Robertson (Eds.), Grandparenthood (pp. 31-48). Beverly Hills: Sage.

Harris, L., \& Associates. (1975). The myth and reality of aging in America. Washington, DC: National Council on the Aging, Inc.

Havighurst, R. J. (1972). Developmental tasks and education. New York: McKay.

House Committee on Education and Labor. (1985). Grandparent rights (Report from the Committee on Education and Labor). Washington, DC: House of Representatives, Ninety-Ninth Congress.

Johnson, C. L. (1985). Grandparenting options in divorcing families: An anthropological perspective. In V. L. Bengtson \& J. F. Robertson (Eds.), Grandparenthood. Beverly Hills, CA: Sage.

Kivett, V. R. (1985). Grandfathers and grandchildren: Patterns of association, helping, and psychological closeness. Family Relations, 34U(4), 565-571.

Kivnick, H. (1981). Grandparenthood and the mental health of grandparents. Aging and Society, 1 (November), 365-391.

Kornhaber, A., \& Woodward, K. L. (1981). Grandparents, grandchildren: The vital connection. Garden City, NJ: Anchor Press/Doubleday.
Lindeman, B. (1988). A grandchild is waiting. 50 Plus, 28(1), 4.

Macionis, J. J. (1987). Sociology. Englewood Cliffs, NJ: Prentice-Hall.

Matthews, S. H., \& Sprey, J. (1984). The impact of divorce on grandparenthood: An exploratory study. The Gerontologist, 24(1), 41-47.

Nahemow, N. (1985). The changing nature of grandparenthood. Medical Aspects of Human Sexuality, 19(4), 81-92.

National Center for Health Statistics. (1979). Vital and health statistics of the United States, 1975, Vol. 1I-marriage and divorce. Washington, DC: U.S. Government Printing Office.

Neugarten, B. L., \& Weinstein, K. K. (1964). The changing American grandparent. Journal of Marriage and the Family, 26, 199-204.

Orr, C. A., \& Van Zandt, S. (1987, May). The role of grandparenting in building family strengths. Paper presented at the Annual National Symposium on Building Family Strengths, Lincoln, NE

Robertson, J. F. (1977). Interaction patterns in three-generation families: Towards a theoretical perspective. International Journal of Aging and Human Development, 6, 103-110.

Spanier, G. B., \& Glick, P. C. (1981). Marital instability in the United States: Some correlates and recent changes. Family Relations, 30, 329-338.

Sprey, J., \& Matthews, S. H. (1982). Contemporary grandparenthood: A systemic transition. Annals of the AAAPSS, 464 (November), 91-103.

Thomas, J. L., \& Datan, N. (1985). Themes of stability and change in grandparenting. Contributions to Human Development, 14, 86-92.

Tinsley, B. R., \& Parke, R. D. (1984). Grandparents as support and socialization agents. In M. Lewis (Ed.), Beyond dyad (pp. 161-194). New York: Plenum Press.

Troll, L. E. (1980). Grandparenting. In L. W. Poon (Ed.), Aging in the 1980's: Psychological issues (pp. 475-484). Washington, DC: American Psychological Association.

Troll, L., Miller, B. J., \& Atchley, R. C. (1979). Families in later life. Belmont, CA: Wadsworth.

Whitley, E., \& Others. (1976). Adopted grandparents: A link between the past and the future. Educational Gerontology, I(3), 243-248.

Wilson, K. B., \& DeShane, M. R. (1982). The legal rights of grandparents: A preliminary discussion. The Gerontologist, 22(1), 67-71

\section{RESOURCES FOR ADDITIONAL INFORMATION}

Grandparents'-Childrens' Rights, Inc., 5728 Bayonne Avenue, Haslett, MI 48840.

Grandparents Anonymous, 1924 Beverly, Pontiac, MI 48055.

Foster Grandparents Program, 806 Connecticut Avenue, NW, Washington, DC 20006.

Foundation for Grandparenting, Paleface, NY.

Jane E. Myers is a professor in the Department of Counselor Education at the University of North Carolina at Greensboro. Novella Perrin is a professor in the Department of Sociology at Central Missouri State University in Warrensburg. Correspondence regarding this article should be sent to Jane E. Myers, Department of Counselor Education, University of North Carolina at Greensboro, 1000 Spring Garden Street, Greensboro, NC 27412. 